EXTENDED REPORT

\title{
Management of osteoarthritis (OA) with an unsupervised home based exercise programme and/or patient administered assessment tools. A cluster randomised controlled trial with a $2 \times 2$ factorial design
}

\author{
P Ravaud, B Giraudeau, I Logeart, J S Larguier, D Rolland, R Treves, L Euller-Ziegler, B Bannwarth, \\ M Dougados
}

Ann Rheum Dis 2004;63:703-708. doi: 10.1136/ard.2003.009803

See end of article for authors' affiliations

Correspondence to:

Dr M Dougados, Service de Rhumatologie, Hôpital

Cochin, 27 rue du Fbg

Saint Jacques, 75014

Paris, France; maxime.

dougados@

cch.ap-hop-paris.fr

Accepted 26 July 2003

\begin{abstract}
Background: Diary recording of pain and disabling activities in osteoarthritis (OA) is widely recommended, but, to our knowledge, its impact on symptoms has not been investigated. Exercise programmes have been shown to be effective when patients are closely supervised by nurses or physiotherapists; however, data are lacking on the efficacy of an unsupervised home based exercise regimen in patients with $O A$.

Objectives: To evaluate the clinical efficacy of patient administered assessment tools and an unsupervised home based exercise programme alone or in combination in patients with OA.

Methods: The study was a 24 week, open cluster randomised controlled trial with a factorial design. Rheumatologists ( $n=867$ ) were assigned to four groups according to the treatment given: standardised tools (ST; $n=220$ ), exercises ( $E X ; n=213)$, both tools and exercises (ST+EX; $n=213)$, or usual care $(n=221)$. Each rheumatologist was to enrol four patients who met the American College of Rheumatology criteria for OA (three with knee OA, one with hip OA). "Tools" consisted of weekly recording of pain and disabling activities in a diary. A home based exercise programme was performed daily at least four times per week with the aid of videotape and booklet. In addition to exercise and asessment, all patients received $12.5 \mathrm{mg}$ or $25 \mathrm{mg}$ of the non-steroidal anti-inflammatory drug rofecoxib once daily. Outcome variables were: pain (measured on a visual analogue scale, 0-100); Western Ontario and McMaster Universities Osteoarthritis Index, function subscale (0-100); and patient assessment of the quality of care (0-100). Results: Overall, 2957 patients with OA (2216 knee, $741 \mathrm{hip}$ ) were included. After 24 weeks, both pain and function improved in the ST, EX, ST+EX, and usual care groups (mean (SD) - 17 (27), - 20 (29), - 15 (27), - 19 (29); and -11 (19), - 12 (19), - 10 (19), - 11 (20), respectively), without significant differences between groups. However, patients in the EX and ST+EX groups were more likely to agree that their rheumatologist had done his best to preserve their functional and physical activities.

Conclusion: Although patients' assessments favoured the exercise programme, results from this study failed to demonstrate a short term symptomatic effect of the two non-pharmacological treatments (weekly recording of condition and exercise) in patients with $O A$ concurrently receiving nonsteroidal antiinflammatory drugs.
\end{abstract}

Abbreviations: $\mathrm{OA}$, osteoarthritis; $\mathrm{RCT}$, randomised clinical trial; VAS visual analogue scale; WOMAC, Western Ontario and McMaster Universities Osteoarthritis Index

Various assessment tools, including the Western Ontario and McMaster Universities Osteoarthritis Index (WOMAC), have been proposed for the assessment of pain and disability in patients with OA. These instruments have been widely employed in clinical research to provide insights into the natural history of OA in groups of patients and to quantify responses to therapy. ${ }^{4}$ However, they have not been widely adopted in rheumatology practice. ${ }^{56}$ Less attention has been given to their potential as guides to the treatment of individual patients, although there is evidence from trials involving patients with other chronic diseases that standard assessment tools may improve patient physician communication and facilitate documentation of the burden of the disease.

We conducted an RCT to examine the impact of an unsupervised home based exercise programme and the use of of the reported studies, the exercise regimens were facility based, supervised, and labour intensive. Supervised exercise is highly resource consuming, which may limit its application to large populations and to a community setting. 
standardised evaluation tools alone or in combination on outcomes in patients with knee and hip OA.

\section{PATIENTS AND METHODS Trial design}

The study was an open cluster RCT with a $2 \times 2$ factorial design and planned duration of 6 months. Rheumatologists, not patients, were randomised. Randomisation was performed centrally using a table of random numbers, by a statistician blinded to the identity of the rheumatologists.

\section{Recruitment of rheumatologists}

A total of 1189 rheumatologists representing approximately $80 \%$ of French rheumatologists were invited by letter to join the study. Those agreeing to participate were assigned to one of the four intervention groups: (a) patient administered assessment tools (standardised tools; ST), $(b)$ home based exercise programme (EX), (c) tools + exercises (ST+EX), or (d) usual care (UC).

\section{Patients}

Each rheumatologist was to enrol four patients with $\mathrm{OA}$ (three with knee OA, one with hip) who met clinical and radiographic American College of Rheumatology criteria for OA. Additional inclusion criteria were $\geqslant 6$ months' history of pain, pain scored by the patient at $\geqslant 30 \mathrm{~mm}$ on a $100 \mathrm{~mm}$ visual analogue scale (VAS), and pain for at least 14 days during the month preceding the study.

Patients were excluded if they (a) had secondary arthritis as defined by Osteoarthritis Research Society International; (b) had comorbidities that precluded their safe involvement in the exercise programme (such as recent myocardial infarction); (c) had surgery scheduled within the 12 months following the start of the study or had serious concomitant illness (neoplasia, infectious disease, unstable metabolic or cardiovascular disease, systemic disease); $(d)$ had received any intra-articular injection (hyaluronic acid, corticosteroid, or joint lavage) during the 3 months preceding the study or had used slow acting anti-osteoarthritic drugs during the 2 months preceding the study; or $(e)$ were participating in another research study.

\section{Ethical approval}

The institutional review board of Cochin Hospital (Paris, France) approved the study. We obtained the consent of each rheumatologist to participate in the study and to accept a quality audit. All patients gave written informed consent.

\section{Interventions}

Standardised tools

To improve communication between the rheumatologist and the patient, rheumatologists were encouraged to use ST of assessment during visits. Pain was quantified on a $100 \mathrm{~mm}$ VAS, and disability was quantified on the WOMAC physical function subscale at each follow up visit. In addition, patients recorded pain and disability every week and discussed these data with the rheumatologist. Based on this information, rheumatologists were encouraged to refine pharmacological treatment during follow up visits at 4 and 12 weeks.

\section{Exercise}

During the initial visit, the rheumatologist gave an oral explanation of the importance of exercise for OA. All patients received a booklet illustrating the exercises and a videotape. The videotape presentation comprised two parts: (a) a motivational portion designed to address the interest of exercise for patients with $\mathrm{OA}$ and to provide positive role models for exercise, and $(b)$ a 30 minute programme of the five exercise routines performed by a trained demonstrator.
The five exercises were designed to improve joint mobility and increase muscle power. These exercises are derived from programmes previously described for $\mathrm{knee}^{7}$ and hip OA, ${ }^{8}$ and are different for each type of OA. All exercises were to be performed at home. Each exercise was initially to be repeated 10 times and, if pain allowed, increased in increments of 5 repetitions each week up to a maximum of 30 . The overall adherence goal was to perform the programme four times each week for 6 months according to an agreed level of resistance. Patients were to record the type and number of exercises performed each session in a logbook provided for that purpose. This logbook was reviewed by the rheumatologist at each visit (at weeks 4 and 12) as a measure of compliance. If participants did not complete their exercise logs, it was assumed they had not exercised.

\section{Usual care}

Patients in this group received medical care as usually provided by individual rheumatologists.

\section{Concomitant therapy}

All patients received the non-steroidal anti-inflammatory drug (NSAID) rofecoxib (Vioxx ${ }^{\circledR}$, Merck, Whitehouse Station, NJ, USA). The drug was administered once daily at $12.5 \mathrm{mg}$ during the first month and thereafter at $25 \mathrm{mg}$ if necessary. Patients were permitted to take acetaminophen if necessary.

\section{Outcome measures}

The primary outcome criterion was the severity of pain on activity during the previous week, as evaluated on a $100 \mathrm{~mm}$ VAS. The secondary endpoints were functional disability, as evaluated on the physical function subscale of the WOMAC scale (score 0-100); patient assessment of overall status, as measured on a $100 \mathrm{~mm}$ VAS; and patient satisfaction with medical care, as assessed by a questionnaire using $100 \mathrm{~mm}$ VAS. This questionnaire was used to assess the quality of care, the management of pain, the management of disabilities, counselling on muscular strengthening, and preservation of physical activity (see table 2 ). Patients were asked to complete this questionnaire at home and return it by mail using a prepaid envelope addressed to a central office. Assessment of efficacy was performed only at 6 months so as not to interfere with the evaluation of ST.

\section{Sample size}

Sample size calculations were predicted on a 10 point reduction in the primary outcome measure (for instance, absolute change in pain VAS), regardless of the intervention and the type of OA (knee or hip), and it was assumed that there would be no intervention interaction. We therefore based our sample size calculations on the comparison of two means (with standard deviation of 60 for hip OA and 90 for knee $\left.\mathrm{OA}^{9}\right)$. The statistical analysis consisted of an overall analysis and two subgroup analyses (knee OA and hip OA). We expected to have at least $80 \%$ power for the overall analysis and $70 \%$ power for the subgroup analyses.

We calculated that a study involving 450 patients with OA of the hip per group would have the $70 \%$ required power to detect a 10 point difference, with a two sided alpha level of $5 \%$. Because each physician was to recruit three patients with knee OA and one with hip OA, this led to the inclusion of 900 physicians and 3600 subjects. The power calculation for 2700 patients with knee OA established that the study had a power estimated at $78.6 \%$ to detect the postulated difference, after adjustment for an intra-cluster correlation (assumed to be 0.05)..$^{11}$ For the overall analysis (3600 patients) the estimated power was $92.3 \%$.

We therefore planned to randomise 900 physicians, each recruiting four patients. 


\section{Statistical analysis}

Analyses were conducted according to a pre-specified plan based on the principle of intent to treat. Missing data were supplied by applying the last observation carried forward procedure, therefore considering that there was no change over the 6 month period. Per protocol analyses were also performed excluding (a) subjects for whom data were not collected at week 24 and $(b)$ subjects who did not comply with one of the interventions and/or rofecoxib therapy. Patients were defined as being compliant with the exercise programme if they performed the routines at least four times a week throughout the study. Patients were defined as being compliant with the ST if they completed their pain and disability diary each week throughout the study.

The primary outcome was analysed in the framework of a mixed effects linear regression model..$^{10}$ A crude analysis was performed, as was one adjusted for the baseline covariates of pain score at the baseline visit, NSAID consumption, radiological grade, presence of $\mathrm{OA}$ in other joints, and location of OA (knee or hip). Changes in the WOMAC score and in the $100 \mathrm{~mm}$ VAS assessing overall patient status were analysed according the same statistical analysis plan. Investigation of patient satisfaction at week 24 was restricted to those patients who answered the satisfaction questionnaire, and a prior arcsine transformation was applied. ${ }^{12}$

Moreover, for each outcome measure, the intra-class correlation coefficient was estimated and an approximate $95 \%$ confidence interval derived by formulas for the balanced case. ${ }^{13}$

Data analyses were carried out with use of SAS (SAS institute Inc, Cary, NC, USA).

\section{RESULTS}

A total of 867 physicians and 2957 patients participated in the study (fig 1). Baseline characteristics of participating patients (2216 with knee OA, 741 with hip OA) are summarised in table 1. A total of $448(15.2 \%)$ patients dropped out of the trial. Reasons for dropping out included inter-current disease of physicians (five patients), intercurrent disease of patients (23 patients), withdrawal of consent (24 patients), dissatisfaction with treatment (184 patients), and no reason (199 patients). The satisfaction questionnaire was not returned by $870(29.4 \%)$ patients. The proportion of non-responder patients was similar in all groups, ranging from $26.8 \%$ in the UC group to $32.1 \%$ in the EX group.

\section{Outcomes}

Table 2 gives the changes for the primary and secondary outcome measures during follow up. In the intent to treat analysis, all four groups showed a significant improvement in pain at 24 weeks $(\mathrm{p}<0.001)$, WOMAC function subscale $(p<0.001)$, and patient assessment of overall status $(\mathrm{p}<0.001)$. The groups did not differ significantly (with or without adjustment) in these three parameters, either in the whole population or in the subgroups of knee or hip OA. For instance, for pain assessment in the whole population, the adjusted effect associated with ST was estimated at $+1.1(95 \%$ confidence interval (CI) -0.7 to $2.9, \mathrm{p}=0.235$ ) and the exercise effect at $+0.8(95 \%$ CI -1.0 to $2.6, p=0.368)$. The results were similar for the per protocol analysis (data not shown).

The intra-class correlation coefficients varied from 0.108 to 0.125 according to the outcome measure chosen. Patients' consumption of acetaminophen was registered at week 4, week 12, or week 24 in $50.3 \%, 57.1 \%, 52.2 \%$, and $57.2 \%$ of patients in the ST, EX, ST+EX, and UC groups, respectively.

\section{Compliance with intervention}

According to the exercise logs, $240(32.6 \%)$ patients in the EX group and $196(28.8 \%)$ in the ST+EX group met the specified criterion of adherence to recommended exercise sessions (at least four times a week during the 6 month period). A further $208(28.3 \%)$ and $191(28.1 \%)$ of patients in these groups performed exercise during the 6 months but for less than four sessions each week, while a further 107 (14.6\%) in the EX group and $131(9.3 \%)$ in the ST+EX group stopped exercise between 3 and 6 months. Among patients who did not adhere to the exercise programme, most (69\%) stopped because they found the exercises too painful or constraining.

Weekly pain and disability diaries were properly completed during the 6 month period by $383(49.0 \%)$ patients in the ST group and $256(37.7 \%)$ patients in the ST+EX group. Among patients in the ST group, a further $168(21.5 \%)$ patients completed log books only for the first 3 months, compared with $132(19.4 \%)$ patients in the ST+EX group. The major causes of incorrect recording or non-recording were inconvenience $(44.6 \%)$, forgetfulness $(24.8 \%)$ and patient perception that they were of no value $(23.2 \%$.).

\section{Patient satisfaction}

The patient satisfaction questionnaire was returned by $70.6 \%$ of patients. Patients in the EX and ST+EX groups were more likely than patients not assigned to exercise therapy to agree with the statements that "the rheumatologists provided advice about muscular strengthening" $(p<0.001)$ and that "the rheumatologist has done his best to preserve their muscular function and their physical activities" $(\mathrm{p}<0.001)$ (table 3). There was no evidence that any intervention materially affected patients' assessment of the quality of care received, or the management of pain and disability (table 3).

\section{DISCUSSION}

The results of our large, practical trial of community derived subjects with knee or hip OA treated with NSAIDs indicate that the use of standardised assessment tools and a minimalist approach to exercise intervention are ineffective in improving pain and function at 6 months. However, our results show that patients in the exercise groups were more likely to consider that their physician did their best to improve their function.

We tried to ensure pragmatic but rigorous evaluation by using a rigorous randomisation procedure and intent to treat analysis. As in other studies concerning exercise therapy, the blinding of both providers and patients was not possible. ${ }^{3}$ The outcomes of our study were self reported, however, and in part were based on answers to a questionnaire returned by mail, thus reducing the likelihood of observers being aware of the groups.

We were convinced that one physician could not counsel one patient to perform physical exercise and not counsel others in a similar way. Consequently, we randomised rheumatologists rather than individual patients, firstly because for such an intervention different patients treated by a same physician cannot be considered as wholly independent, and secondly to avoid contamination between interventions and control participants. ${ }^{14}$ The values observed empirically for the intra-class correlation coefficient (0.108 to 0.125 ) suggest that our approach was substantially sound. Cluster randomisation trials are subject to bias due to selection," ${ }^{11}$ but the large number of clusters (nearly 900) randomised in this trial offers the best achievable protection against such bias. Moreover, we sought to eliminate one potential confounding factor, lack of adequate control for concomitant treatments, by standardising NSAID treatment. It remains possible that confounding factors not controlled by cluster randomisation or adjustment explain the apparent 


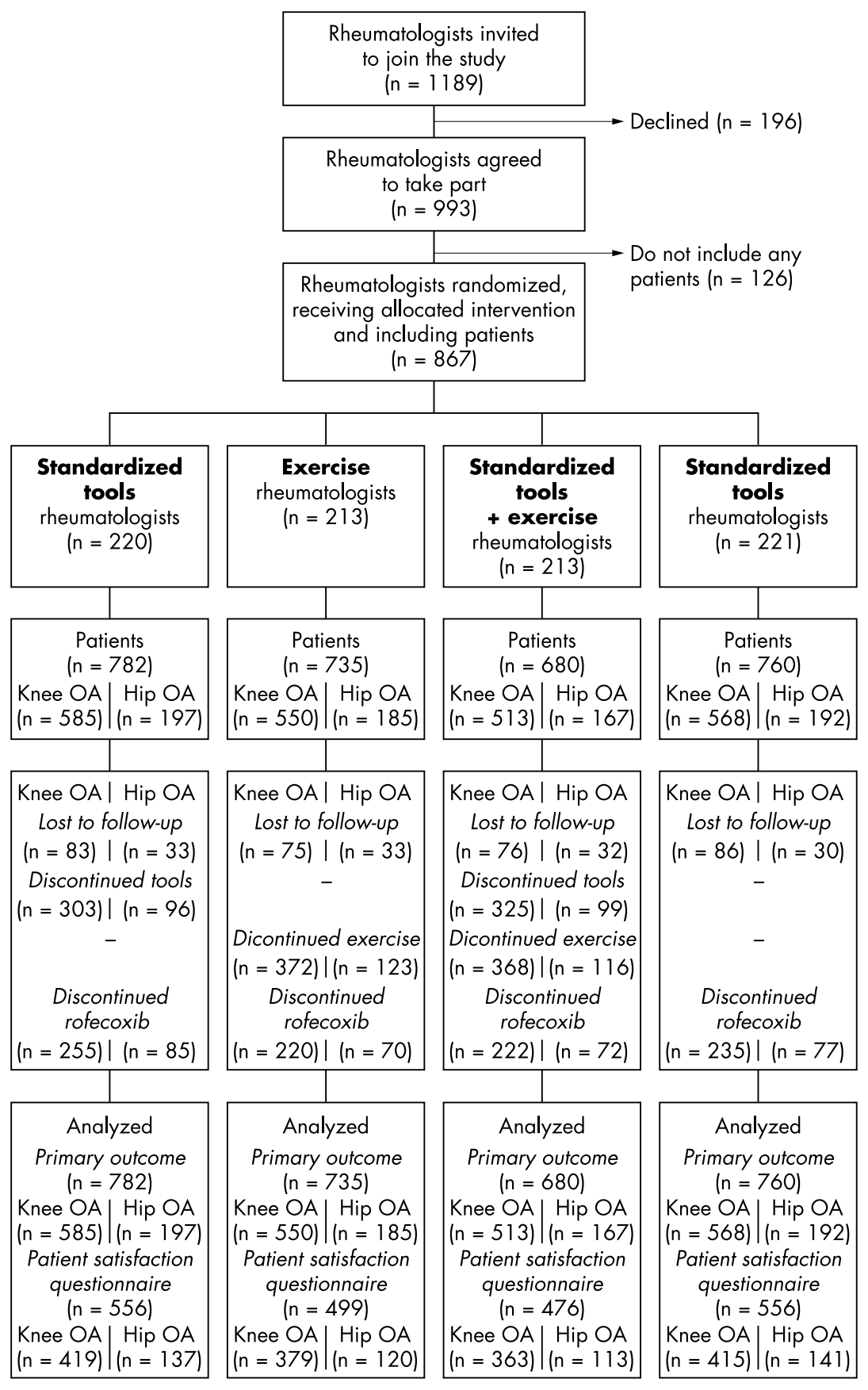

Figure 1 Study flow chart.

lack of effect, but no candidate factors were identified. Our study is a "true negative" study ${ }^{15}$ because, although statistically non-significant, our results remain conclusive.

Our results are not consistent with those of previous studies of exercise regimens that have shown improvement in pain and disability. Most of these studies report small to moderate effects for these parameters, but the magnitude of improvement in pain and disability is variable among studies. ${ }^{36-19}$ Caveats of all these studies have been emphasised. ${ }^{320} 21$ Their sample sizes have been small ( $<100$ per arm except for two studies), the durations have been short (12 weeks or fewer except for two studies), and many lacked a true control group that received equivalent physician time and attention. In addition, numerous studies failed to control adequately for concomitant treatment and frequently lacked an intent to treat analysis. All these factors could result in an overestimation of treatment effects. Finally, the beneficial effects of exercise slowly declined after 12 weeks. ${ }^{22}$

Several explanations could explain our results. Firstly, and perhaps most important, the exercise programme was unsupervised. Eight of the 11 studies on this topic were facility based and supervised. ${ }^{3}$ Our approach was associated with a high rate of non-compliance; $60 \%$ of patients performed exercise during the 6 month period, but two thirds of the patients did not attain the specified adherence standard of four exercise sessions per week. Many of the nonadherent patients indicated that the exercise programmes were troublesome and constraining. In comparison, in a recent highly supervised study ( $1-3$ physiotherapy sessions a week) $66 \%$ of the patients reported at 24 weeks having exercised often or very often. ${ }^{22}$ Faulty execution of the 
Table 1 Demographic and clinical characteristics of patients with osteoarthritis of the knee or hip at baseline according to rheumatologist groups randomised by intervention

\begin{tabular}{|c|c|c|c|c|c|c|c|c|}
\hline \multirow[b]{3}{*}{ Patient characteristics } & \multicolumn{8}{|c|}{ Rheumatologist intervention groups } \\
\hline & \multicolumn{2}{|c|}{ Standardised tools $(n=782)$} & \multicolumn{2}{|c|}{ Exercise $(n=735)$} & \multicolumn{2}{|c|}{$\begin{array}{l}\text { Standardised tools }+ \\
\text { exercise }(n=680)\end{array}$} & \multicolumn{2}{|c|}{ Usual care $(n=760)$} \\
\hline & Hip $(n=197)$ & Knee $(n=585)$ & Hip $(n=185)$ & $\begin{array}{l}\text { Knee } \\
(n=550)\end{array}$ & Hip $(n=167)$ & $\begin{array}{l}\text { Knee } \\
(n=513)\end{array}$ & Hip $(n=192)$ & Knee $(n=568)$ \\
\hline Age mean $(\mathrm{SD})$, years & $64.1(10.8)$ & $68.1(10.5)$ & $63.8(9.9)$ & $68.0(9.9)$ & $62.8(8.9)$ & $66.5(10.5)$ & $65.1(10.7)$ & $68.1(10.2)$ \\
\hline Age $>75$ years, no. (\%) & $34(17.4)$ & $158(27.1)$ & $23(12.5)$ & $131(23.9)$ & $17(10.2)$ & $104(20.3)$ & $32(16.7)$ & $150(26.4)$ \\
\hline Male, no. (\%) & $75(38.1)$ & 159 (27.2) & $72(38.9)$ & $143(26.0)$ & $65(38.9)$ & 160 (31.2) & $69(35.9)$ & $140(24.6)$ \\
\hline $\mathrm{BMI}$ mean $(\mathrm{SD})^{*}$ & $26.3(3.9)$ & $28.2(5.1)$ & $26.0(3.9)$ & $28.3(5.4)$ & $26.2(4.3)$ & $28.1(4.9)$ & $26.4(4.3)$ & $28.4(5.2)$ \\
\hline $\begin{array}{l}\text { Mean duration of symptoms (SD), } \\
\text { (months) }\end{array}$ & $53.8(62.0)$ & $76.5(83.2)$ & $59.9(68.4)$ & $72.3(73.3)$ & $53.4(63.7)$ & $76.9(80.2)$ & $51.3(54.4)$ & $72.1(77.9)$ \\
\hline Mean (SD) VAS pain $(0-100)^{*}$ & $54.4(16.8)$ & $56.8(17.2)$ & $57.7(15.8)$ & 59.7 (18.2) & 53.0 & $54.6(16.8)$ & $57.2(16.4)$ & 60.4 \\
\hline Mean WOMAC function score $(0-100)^{*}$ & * $45.5(15.6)$ & 44.5 (18.7) & $44.9(15.7)$ & $45.4(18.8)$ & 41.7 (17.0) & $43.1(18.3)$ & $45.6(17.8)$ & 45.7 (18.8) \\
\hline $\begin{array}{l}\text { Patient global assessment (SD) }(0-100)^{*} \\
\text { Radiological grade (Kellaren and }\end{array}$ & * $56.3(18.5)$ & 57.3 & $60.8(18.8)$ & $61.0(21.1)$ & $55.3(17.3)$ & $56.6(19.4)$ & $60.7(18.6)$ & $61.3(19.9)$ \\
\hline \multicolumn{9}{|l|}{$\begin{array}{l}\text { Radiological grade (Kellgren and } \\
\text { Lawrence) }\end{array}$} \\
\hline II & 35 (17.8) & $85(14.5)$ & $40(21.6)$ & $86(15.7)$ & $33(19.8)$ & $85(16.6)$ & $36(18.7)$ & 93 (16.4) \\
\hline III & $105(53.3)$ & $262(44.8)$ & $100(54.1)$ & $261(47.5)$ & $83(49.7)$ & $227(44.2)$ & $104(54.2)$ & $258(45.4)$ \\
\hline IV & $57(28.9)$ & $238(40.7)$ & 45 (24.3) & $202(36.8)$ & $51(30.5)$ & $201(39.2)$ & $52(27.1)$ & $217(38.2)$ \\
\hline Osteoarthrtitis in other joints, no (\%) & 176 (93.12) & 550 (94.83) & $162(89.50)$ & $504(92.99)$ & $150(91.46)$ & 476 (93.52) & $166(89.25)$ & $520(93.86)$ \\
\hline \multicolumn{9}{|l|}{ Prior treatment } \\
\hline NSAIDs, no. (\%) & $131(66.5)$ & $354(60.5)$ & $115(62.2)$ & $354(64.3)$ & $123(73.6)$ & $349(68.1)$ & $125(65.1)$ & $361(53.6)$ \\
\hline SYSADOA, no. (\%) & $73(37.1)$ & $237(40.5)$ & $78(42.2)$ & $243(44.2)$ & $74(44.3)$ & $221(43.1)$ & $75(39.1)$ & $221(38.9)$ \\
\hline IA treatment, no. (\%) & $10(5.1)$ & $235(40.2)$ & $3(1.6)$ & $214(38.9)$ & $1(0.6)$ & $186(36.3)$ & $9(4.7)$ & $208(36.6)$ \\
\hline $\begin{array}{l}\text { intra-class correlation coefficient (ICC), w } \\
\text { and } 0.177 \text { for patient global assessment } \\
\text { NSAID, non-steroidal anti-inflammatory }\end{array}$ & which was 0 . & for age, & . & for & $f$ s) & $185 \mathrm{f}$ & sity, & $\begin{array}{l}\text { (2.6) and } \rho \text { is the } \\
213 \text { for WOMAC }\end{array}$ \\
\hline
\end{tabular}

exercises might have reduced their effectiveness even in patients whose compliance was good. Secondly, differences in the type of exercises might have contributed to the difference from results of previous studies. In addition, the chosen exercise programme was perhaps less effective than those proposed by others. We cannot exclude this possibility, particularly for the hip exercises, which were not previously tested against a placebo. Thirdly, the substantial improvement in the UC group could partly explain our results. This improvement might be explained by the fact that patients, even in the UC group, had entered a clinical trial and were receiving a new pharmacological drug (rofecoxib in this study). Greater attention from healthcare providers may be sufficient to improve symptoms in patients with $\mathrm{OA}^{23}{ }^{24}$ and may have contributed to the improvement in pain and

Table 2 Assessment of pain and disability, and global assessment of disease (crude differences from baseline) by patients with osteoarthritis of the knee or hip treated by rheumatologists randomised to four groups according to intervention



Results are mean (SD), with SD corrected with the inflation coefficient $\sqrt{1+(\bar{m}-1)}$, where $\bar{m}$ is the mean size of the cluster (3.4) and $\rho$ is the intra-class correlation coefficient equalling 0.108 for pain, 0.125 for WOMAC, and 0.121 for global assessment.

ST, standardised tools; EX, exercise; UC, usual care; VAS, visual analogue scale. mobility reported by the UC group. In addition, many patients in this group received counselling about muscular strengthening, which could have contributed to diluting the treatment effect and reducing the point estimate of the effectiveness of the exercise regimen.

The use of standardised outcome measurements and self recording of pain and disability in routine clinical practice are widely proposed for documenting the short term effect of

Table 3 Assessment of satisfaction on five $100 \mathrm{~mm}$ visual analogue scales by patients treated by rheumatologists randomised to four groups of intervention for osteoarthritis of the knee or hip

\begin{tabular}{|c|c|c|c|c|}
\hline \multirow[b]{2}{*}{ Measurements } & \multicolumn{4}{|c|}{ Rheumatologist intervention groups } \\
\hline & $\begin{array}{l}\text { ST } \\
(n=556)\end{array}$ & $\begin{array}{l}\text { EX } \\
(n=499)\end{array}$ & $\begin{array}{l}\mathrm{ST}+\mathrm{EX} \\
(\mathrm{n}=476)\end{array}$ & $\begin{array}{l}\text { UC } \\
(n=556)\end{array}$ \\
\hline $\begin{array}{l}\text { According to your expectation, } \\
\text { the quality of care was:* } \\
\text { Your pain was taken into } \\
\text { account: } \dagger \\
\text { Your disabilities during daily } \\
\text { living activities was taken into } \\
\text { account: } †\end{array}$ & $\begin{array}{l}68.0 \\
(24.0) \\
84.9 \\
(16.8) \\
84.1 \\
(17.5)\end{array}$ & $\begin{array}{l}67.9 \\
(25.5) \\
85.4 \\
(17.0) \\
85.3 \\
(17.5)\end{array}$ & $\begin{array}{l}69.1 \\
(24.6) \\
85.3 \\
(17.7) \\
85.3 \\
(17.0)\end{array}$ & $\begin{array}{l}66.6 \\
(25.1) \\
85.7 \\
(17.4) \\
85.3 \\
(17.1)\end{array}$ \\
\hline $\begin{array}{l}\text { Have you received counselling } \\
\text { about muscular strengtheningt } \\
\text { According to you, your } \\
\text { physician has done his best to } \\
\text { preserve your muscular function } \\
\text { and physical activities despite } \\
\text { your osteoarthritis: } †\end{array}$ & $\begin{array}{l}72.0 \\
(36.8) \\
75.9 \\
(28.2)\end{array}$ & $\begin{array}{l}87.1 \\
(18.2) \\
84.5 \\
(21.0)\end{array}$ & $\begin{array}{l}86.3 \\
(20.2) \\
85.0 \\
(19.5)\end{array}$ & $\begin{array}{l}72.8 \\
(36.9) \\
75.6 \\
(29.7)\end{array}$ \\
\hline \multicolumn{5}{|c|}{$\begin{array}{l}\text { *Scale running from "greatly lower than expected" }(0) \text { to "greatly higher } \\
\text { than expected" }(100) \text {. } \\
\text { †Scale running from "not at all" (0) to "yes, completely" (100). } \\
\text { Results are expressed as mean (SD), with SD corrected with the inflation } \\
\text { coefficient } \sqrt{1+(\bar{m}-1)} \text {, where } \bar{m} \text { is the mean size of cluster }(2.7) \text { and } \rho \\
\text { is the intra-class correlation coefficient equalling } 0.062,0.205,0.203 \text {, } \\
0.381 \text {, and } 0.239 \text { for questions } 1 \text { to } 5 \text {, respectively. } \\
\text { ST, standardised tools; EX, exercise; UC, usual care; VAS, visual } \\
\text { analogue scale. }\end{array}$} \\
\hline
\end{tabular}


treatment changes and monitoring disease progression. However, in our short term study the use of these instruments appeared to reduce rather than enhance adherence with the exercise programme. Given that the inconvenience of exercise figured prominently among the reasons for non-adherence, it may be surmised that the additional burden of the weekly self assessments was counterproductive in encouraging patients to persevere with exercise. In the UC groups, previous habits of the rheumatologist who routinely used a standardised questionnaire such as the Lequesne Index or simply asked patients if they were better during the follow up could perhaps explain these results. The use of such tools, which provide quantitative data for comparison of the same patient between visits, ${ }^{25}$ could be more beneficial in long term follow up or for critical decisions such as total hip or knee replacement, ${ }^{26}$ but additional studies will be needed to test this supposition. Another reason for the absence of an effect with unsupervised exercise or standardised tools plus rofecoxib could be that the response of OA, as gauged by the instruments used in this study, is a net zero paradigm in which there is a limit to the degree of benefit that may be discerned, and once that limit is reached, no further improvement will be seen regardless of what other interventions are used.

Despite the results of this study, we consider that patients with OA should be encouraged to exercise regularly because of the benefits of exercise for other aspects of chronic disabling disease (such as obesity), and the potential for improving the range of motion and muscular strength, which are important influences on outcome in patients undergoing total hip or knee replacement. ${ }^{27}$ However, there is an unresolved difficulty between the benefits of exercise programmes and their practicability. Our results indicate that unsupervised exercise schedules are ineffective and the use of a motivational videotape appears in itself insufficient. It probably would be unrealistic to provide resource intensive hospital based programmes for most patients with mild to moderate OA, therefore, the modalities of an exercise programme should be improved to fit our needs: efficacy and generalisability. Two courses could be proposed: $(a)$ the use of a simpler, easier to perform, exercise programme, such as walking, ${ }^{29}$ or $(b)$ an increased level of supervision by trained nurses or physiotherapists to improve patient motivation and compliance. Future studies are required to identify effective exercise protocols that can be used routinely in daily care of community patients.

\section{ACKNOWLEDGMENTS}

We appreciate the work of W Thompson and D Bröner in preparing the manuscript. This study was supported by Merck Sharp \& Dohme, Chibret, France.

\section{Authors' affiliations}

P Ravaud, Département d'Epidémiologie et de Biostatistique, Hôpital Bichat, Faculté Xavier Bichat, Université Paris 7, Paris et INSERM U444, Paris, France

B Giraudeau, Centre de Recherche Clinique, Faculté de Tours, France et INSERM U444, France

I Logeart, Laboratoire Merck Sharp \& Dhome-Chibret, France J S Larguier, RCTS, France

D Rolland, Service de Rhumatologie, CHG Bourges, Bourges, France R Treves, Service de Rhumatologie et Thérapeutique, CHU Dupuytren, Limoges, France

L Euller-Ziegler, Service de Rhumatologie, CHU l'Archet, Nice, France B Bannwarth, Service de Rhumatologie, Groupe Hospitalier Pellegrin, Bordeaux, France

M Dougados, Service de Rhumatologie, Hôpital Cochin et Faculté Cochin, Paris, France

\section{REFERENCES}

1 Pendleton A, Arden N, Dougados M, Doherty M, Bannwarth B, Biilsma JW, et al. EULAR recommendations for the management of knee osteoarthritis: report of a task force of the Standing Committee for International Clinical Studies including therapeutic trials (ESCISIT). Ann Rheum Dis 2000;59:936-44.

2 Recommendations for the medical management of osteoarthritis of the hip and knee: 2000 update. American College of Rheumatology Subcommittee on Osteoarthritis Guidelines. Arthritis Rheum 2000:43:1905-15.

3 Van Baar ME, Assendelft WJ, Dekker J, Oostendorp RA, Biilsma JW Effectiveness of exercise therapy in patients with osteoarthritis of the hip or knee: a systematic review of randomised clinical trials. Arthritis Rheum 1999:42:1361-9.

4 McConnell S, Kolopack P, Davis AM. The Western Ontario and McMaster Universities Osteoarthritis Index (WOMAC): a review of its utility and measurement properties. Arthritis Rheum 2001;45:453-61.

5 Bellamy N, Kaloni S, Pope J, Coulter K, Campbell J. Quantitative rheumatology: a survey of outcome measurement procedures in routine rheumatology outpatient practice in Canada. J Rheum 1998;25:852-8.

6 Bellamy N, Murden KD, Brooks PM, Baraclough D, Tellus MM, Campbell J. A survey of outcome measurement procedures in routine rheumatology outpatient practice in Australia. J Rheumatol 1999;26:1593-9.

7 O'Reilly SC, Muir KR, Doherty M. Effectiveness of home exercise on pain and disability from osteoarthritis of the knee: a randomised controlled trial. Ann Rheum Dis 1999;58:15-19.

8 Green J, McKenna F, Redfern EJ, Chamberlain MA. Home exercises are as effective as outpatient hydrotherapy for osteoarthritis of the hip. BrJ Rheumatol 1993:32:812-15

9 Dougados M, Leclaire P, Van der Heijde D, Bloch DA, Bellamy N, Altman RD. Response criteria for clinical trials on osteoarthritis of the knee and hip: a report of the Osteoarthritis Research Society International Standing Committee for Clinical Trials response criteria initiative. Osteoarthritis Cartilage 2000;8:395-403.

10 Donner A, Klar N. Design and analysis of cluster randomization trials in health research. London: Arnold, 2000.

11 Murray DM. Design and analysis of group-randomized trials. New York: Oxford University Press, 1998

12 Aitken RC. Measurement of feelings using visual analogue scales. Proc R Soc Med 1993;62:989-93.

13 Donner A, Wells GA. Comparison of confidence interval methods for the intraclass correlation coefficient. Biometrics 1986:42:401-12.

14 Torgerson DJ. Contamination in trials: is cluster randomisation the answer? BMJ 2001;322:356-7.

15 Makuch RW, Johnson MF. Some issues in the design and interpretation of "negative" clinical studies. Arch Intern Med 1986;146:986-9.

16 Hurley MV, Scott DL. Improvements in quadriceps sensorimotor function and disability of patients with knee osteoarthritis following a clinically practicable exercise regime. Br J Rheumatol 1998;37:1181-7.

17 Messier SP, Royer TD, Craven TE, O'Toole ML, Burns R, Ettinger WH Jr. Longterm exercise and its effect on balance in older, osteoarthritic adults: results from the Fitness, Arthritis, and Seniors Trial (FAST). J Am Geriatr Soc 2000;48:131-8.

18 Deyle GD, Henderson NE, Matekel RL, Ryder MG, Garber MB, Allison SC. Effectiveness of manual physical therapy and exercise in osteoarthritis of the knee. A randomized, controlled trial. Ann Intern Med 2000;132:173-81.

19 Petrella RJ, Bartha C. Home based exercise therapy for older patients with knee osteoarthritis: a randomized clinical trial. J Rheumatol 2000;27:2215-21.

20 Baker K, McAlindon T. Exercise for knee osteoarthritis. Curr Opinion Rheumatol 2000;12:456-63.

21 Perkins PJ, Doherty M. Nonpharmacologic therapy of osteoarthritis. Curr Rheumatol Rep 1999;1:48-53.

22 van Baar ME, Dekker J, Oostendorp RA, Bijl D, Voorn TB, Bijlsma JW. Effectiveness of exercise in patients with osteoarthritis of hip or knee: nine months' follow up. Ann Rheum Dis 2001;60:1123-30.

23 Weinberger $M$, Tierney WM, Booher $P$, et al. Can the provision of information to patients with osteoarthritis improve functional status? Arthritis Rheum 1989;32:1577-83.

24 Rene J, Weinberger M, Mazzuca SA, et al. Reduction of joint pain in patients with knee osteoarthritis who have received monthly telephone calls from lay personnel and whose medical treatment regimens have remained stable. Arthritis Rheum 1992;35:511-15.

25 Wolfe F, Pincus T. Standard self-report questionnaires in routine clinical and research practice. An opportunity for patients and rheumatologists. J Rheum $1991 ; 18: 643-646$

26 Brazier JE, Harper R, Munro J, Walters SJ, Snaith ML. Generic and conditionspecific outcome measures for people with osteoarthritis of the knee. Rheumatol 1999;38:870-7.

27 Fortin PR, Clarke AE, Joseph L, Liang MH, Tanzer M, Ferland D, Phillips C, Partridge AJ, Belisle P, Fossel AH, Mahomed N, Sledge CB, Katz JN. Outcomes of total hip and knee replacement: preoperative functional status predicts outcomes at six months after surgery. Arthritis Rheum 1999:42:1722-8.

28 Lizaur A, Marco L, Cebrian R. Preoperative factors influencing the range of movement after total knee arthroplasty for severe osteoarthritis. J Bone Joint Surg $\mathrm{Br}$ 1997;79:626-9.

29 Ettinger WH, Burns R, Messier SP, Applegate W, Rejeski WJ, Morgan T, et al. A randomized trial comparing aerobic exercise and resistance exercise with a health education program in older adults with knee osteoarthritis. JAMA 1997;277:25-9. 